\title{
FAMÍLIA, CRIATIVIDADE E PRAZER NO OFÍCIO: ETNOGRAFIA DA APRENDIZAGEM EM UMA MARCENARIA NA AMAZÔNIA
}

\author{
Luiz Francisco Loureiro (D) $\triangle$
}

Universidade do Estado do Amazonas I Tefé - AM - Brasil

Ana Claudeise Silva do Nascimento $ه$

Instituto de Desenvolvimento Sustentável Mamirauá | Tefé - AM - Brasil

Marilia de Jesus da Silva e Sousa (1)

Nelissa Peralta $ه$ 


\section{RESUMO}

Este artigo discute aspectos do aprendizado como meio de reprodução do ofício de marceneiro, em uma cidade do interior do estado do Amazonas. Por meio da observação do contexto e do levantamento de evidências orais, buscamos conhecer as dimensões técnicas e simbólicas desta prática social que circulam entre os membros de uma comunidade de praticantes. Os resultados obtidos sugerem que, do ponto de vista técnico, os principais itens ali aprendidos são o diagnóstico de situações e a aplicação de técnicas adequadas para a resolução de problemas comuns a este ofício. Já do ponto de vista simbólico, é o aprendizado de valores necessários e as percepções sobre o ofício em relação à sociedade que possuem maior ênfase. Finalmente, apontamos como as principais características do ofício de marceneiro, no contexto analisado, suas dimensões familiares e criativas, que conferem a esta prática social a qualificação de prazerosa entre seus praticantes.

Palavras-chave: aprendizado; identidade profissional; artesãos.

\section{FAMILY, CREATIVITY AND PLEASURE IN THE CRAFT: ETHNOGRAPHY OF LEARNING IN A WOODWORK IN THE AMAZON}

\section{ABSTRACT}

This article discusses aspects of learning as a means of reproduction of the woodworker's craft in a town in the interior of the state of Amazonas. Through observation of the context and the collection of oral evidence, we seek to know the technical and symbolic dimensions of this social practice among the members of a community of practitioners. The results obtained suggest that, from a technical point of view, the main items learned are the diagnosis of situations and the application of adequate techniques to solve common problems of this craft. From the symbolic point of view, learning the necessary values and the perceptions about the craft in relation to the society have greater emphasis. Finally, we point out as the main characteristics of woodwork craft, in the analyzed context, its familiar and creative dimensions, which confer to this social practice the qualification of pleasure among its practitioners.

Keywords: learning; professional

identity; craftsperson

\section{FAMILIA, CREATIVIDAD Y PLACER EN EL OFICIO: ETNOGRAFÍA DEL APRENDIZAJE EN UNA CARPINTERÍA EN LA AMAZONIA}

\section{RESUMEN}

Este articulo discute los aspectos del aprendizaje como medio de reproducción del oficio de carpintero en una ciudad del interior del estado de Amazonas. Mediante observación del contexto y levantamiento de evidenicas orales, buscamos conocer las dimensiones técnicas y simbólicas de esta práctica social que circulan entre los miembros de una comunidad de practicantes. Los resultados sugieren que, desde el punto de vista técnico, los principales factores aprendidos son el análisis de situaciones y la aplicación de técnicas adecuadas para solucionar problemas comunes a la práctica del oficio. Del punto de vista simbólico, poseen mayor enfasis el aprendizaje de valores indispensables y las percepciones sobre el oficio con relación a la sociedad. Finalmente, señalamos las dimensiones familiares y creativas como las principales características del oficio de carpintero, en el contexto analizado, las cuales hacen que los practicantes le confieran a esta práctica social la calificación de placentera.

Palabras clave: aprendizaje; 


\section{INTRODUÇÃO}

A marcenaria é, como sugere Emília Ribeiro (1950), um ofício tradicional, cujas origens remetem ao longínquo período em que os humanos deixaram de se preocupar apenas com o abrigo contra intempéries e inimigos, e passaram a se dedicar ao conforto e à praticidade de suas moradias. Trata-se de um ofício que exige de seus praticantes domínio sobre um processo de produção em que o maquinário e as ferramentas utilizadas são determinantes para o ritmo e a forma de trabalho. No mesmo sentido, ao praticante da marcenaria, exige-se habilitação para a feitura de objetos, cuja produção, diferente do modo de produção capitalista, tem alto grau de dependência das habilidades do trabalhador. Assim, ainda que seja realizada entre as mais variadas sociedades ao longo da história e ao redor do mundo, a marcenaria não pode ser considerada uma prática unívoca, pois apresenta importantes variações, de acordo com os contextos em que é praticada (Ribeiro 1950).

Em Tefé, um município situado no estado do Amazonas, na região do médio rio Solimões, fatores como a oferta de madeira de boa qualidade, a existência de pequenos grupos de prática bem estruturados e a ausência de grandes empresas moveleiras permitem que esta prática social ainda sobreviva com características familiares e semiartesanais. Por exemplo, na oficina de Raimundo, nosso contexto etnográfico, os principais produtos são portas, batentes, mesas, cômodas, prateleiras e araras para pendurar cabides. Além disso, como pretendemos demonstrar a seguir, neste espaço de trabalho também se produz aprendizado, pois é na prática diária que os personagens desta etnografia da aprendizagem criam e recriam o tradicional ofício de marceneiro.

Entre as 25 oficinas de marcenaria de Tefé (Marcos \& Peralta 2016), este grupo de prática foi escolhido como objeto desta etnografia da aprendizagem por reunir certas características que o tornam um caso interessante. Uma delas é o seu longo período de existência, pois seu fundador, a despeito de mudanças na composição do grupo, trabalha no mesmo lugar há pelo menos trinta anos, o que configura a oficina de Raimundo como uma das mais antigas em atividade na cidade. Além disso, consideramos que fatores presentes nesta oficina, como o número reduzido de praticantes reunidos e o trabalho por meio de encomendas, são ilustrativos em relação à forma mais comum das oficinas de marcenaria da região, fazendo da oficina de Raimundo uma boa amostra quanto a questões pertinentes também às suas congêneres, no mesmo contexto.

É nas ideias de que a cultura se aprende e de que o aprendizado de técnicas e de significados coletivos é um fator indispensável para a existência das práticas sociais que encontramos a justificativa para a realização deste trabalho. Consideramos, assim, que o estudo do fenômeno do aprendizado, nos moldes como buscamos realizá-lo, é uma forma de lançar luz sobre a reprodução das práticas sociais e dos grupos de praticantes. Além dessa razão, outra importante fundamentação para este estudo é o conhecimento e a apresentação das perspectivas dos próprios sujeitos, dos menos aos mais experientes, sobre sua identificação com o ofício que praticam e as dificuldades que encontram para exercê-lo. 
O objetivo principal deste estudo etnográfico foi descrever e interpretar o processo de reprodução do ofício de marceneiro. Podemos elencar também uma série de objetivos secundários, que possibilitaram a construção de nossa descrição interpretativa: o conhecimento do espaço da aprendizagem em questão e das características dos sujeitos envolvidos; do contexto social de desenvolvimento da prática aprendida e do sistema de relações nele desenvolvido; e de como e o que se aprende, e quais as motivações para aprender.

Este estudo foi desenvolvido em duas etapas. Na primeira, em 2017, ao longo de uma semana de observação na oficina, foi coletada a maior parte dos dados, empregados em uma versão preliminar deste artigo. Na segunda, já em 2018, retornamos ao contexto etnografado, com o intuito de coletar as opiniões dos marceneiros sobre a primeira versão do manuscrito e obtivemos dados adicionais que permitiram maior detalhamento de nossas análises. É importante assinalar, a respeito da identidade dos marceneiros envolvidos, que optamos pelo uso de seus nomes verdadeiros, e que essa escolha se deu mediante consulta e autorização deles. Com isso, pretendemos dar espaço para a continuidade das relações destes artesãos com suas ideias sobre o ofício que desenvolvem.

A metodologia desenvolvida para alcançar o objetivo de compreender aspectos da reprodução da marcenaria como um ofício esteve baseada na observação direta e na realização de conversas durante o trabalho dos artesãos marceneiros. Na observação, tendo como base a ideia de etnografia defendida por Clifford Geertz (1989), empregamos nossa atenção para descrever e interpretar o comportamento dos praticantes durante o desempenho de suas tarefas. Nesses momentos, tínhamos em vista, sobretudo, a compreensão do sistema de relações, o uso do espaço e do maquinário pelos praticantes e a identificação da forma como o aprendizado contribui para a reprodução das técnicas do ofício de marceneiro.

As conversas, por outro lado, foram conduzidas de forma menos sistemática, em meio à realização das tarefas diárias ou em pequenas pausas para descanso, o que conferiu um caráter menos formal para o processo de levantamento de dados, em comparação com a realização de entrevistas. A vantagem desta estratégia foi que alguns assuntos surgiram mesmo sem que houvesse o estímulo de perguntas mais ou menos estruturadas, com os praticantes dizendo espontaneamente o que achavam da marcenaria ou das tarefas que realizavam.

O texto que segue é composto por duas seções: a primeira é um apanhado teórico, que visa esclarecer as premissas e os conceitos que orientaram tanto a observação quanto a análise do contexto de aprendizagem etnografado; a segunda é a apresentação dos resultados da pesquisa e traz a discussão sobre o contexto ora debatido, revelando nossas impressões e considerações sobre a aprendizagem do ofício de marceneiro na comunidade de praticantes estudada.

\section{OS CONCEITOS E O CONTEXTO}

A noção de aprendizagem que norteou nossas observações é aquela que entende o aprendizado como um fenômeno difuso e onipresente no tempo e no espaço (Gomes 2014). Não há, portanto, momento ou lugar mais apropriados ou exatos para a aprendizagem. Aprendemos quando alguém 
nos ensina, mas também enquanto observamos, executamos ou discutimos determinada prática. No contexto analisado, isso significa assumir que Timóteo, o marceneiro com menor experiência em nosso contexto etnográfico, aprende marcenaria todos os dias, todo o tempo que passa trabalhando. Não apenas ele, mas todos que estavam ali, inclusive os mais experientes, vivem um processo contínuo de aprendizado. Isso, sem dúvida, torna a tarefa da antropologia da aprendizagem mais complexa, mas também deve fazer com que seus resultados sejam mais instigantes e completos.

Compreendemos que a forma das relações pelas quais se ensina e se aprende é a da educação da atenção, rejeitando, portanto, a visão equivocada de que o conhecimento pode ser transmitido de um para outro indivíduo (Ingold 2010). O que há, nos casos em que o aprendizado é decorrente de uma relação de ensino, é uma espécie de orientação, a educação da atenção do aprendiz pela experiência do instrutor. No contexto observado, essa educação era expressa, por exemplo, durante as conversas de Timóteo e de Raimundo a respeito dos trabalhos realizados. É por ter mais apurada a educação de sua atenção para assuntos de marcenaria que Raimundo pode estar em uma posição central no grupo de praticantes, o que significa, do ponto de vista teórico, que ele possui conhecimentos e habilidades suficientes para reunir ao seu redor um grupo de praticantes iniciados e iniciantes no ofício.

Outra ideia importante sobre o aprendizado é a de que este fenômeno tem "a exploração e a mudança" como suas características principais (Bateson 1986:55), de tal modo que a aprendizagem é uma forma contínua de troca de informações entre o contexto, sempre se renovando, e os indivíduos. É, portanto, na relação com os contextos que aprendemos. Assim, tanto Timóteo quanto Raimundo estão constantemente aprendendo, porque, inseridos em seu contexto de prática, os marceneiros se deparam diariamente com situações novas e exploram possibilidades dentro de seu ofício. Daí vem a importância de estar em contato com aquilo que se pretende aprender, para se tornar experiente em determinada prática social.

É interessante dar relevo também à ideia de que a aprendizagem envolve a construção de identidades, ou seja, envolve relações de longo prazo entre pessoas, bem como a filiação social a uma comunidade de prática (Lave \& Wenger 1991). Com a aprendizagem, a pessoa muda a si mesma e, ao mesmo tempo, transforma a sua comunidade de prática. Ter isso em mente nos ajuda a pensar na aprendizagem para além dos sujeitos aprendizes, nos obrigando a olhar as relações por eles desenvolvidas em seus contextos de prática.

Metodologicamente, a abordagem da "aprendizagem situada", um conceito elaborado por Jean Lave \& Etienne Wenger (1991), demanda a descrição da organização sociocultural do espaço onde a atividade e a circulação de experiência ocorrem, o que significa que, como observadores da aprendizagem, é importante que voltemos nossos olhares para conflitos, interesses, significados e motivações compartilhados pelos praticantes.

Ainda a respeito do aprendizado, é importante estar atento ao fato de que ele "é uma dimensão integral e inseparável das práticas sociais" (Lave \& Wenger 1991:2). É por meio do aprendizado que tais práticas se perpetuam e renovam seus 
quadros de praticantes, assim como suas técnicas. Em síntese, a reprodução de comunidades de praticantes é o sustentáculo das práticas sociais, e o seu meio de acontecer é o aprendizado.

Outros conceitos úteis para nossas análises foram os de "prática social", "comunidade de praticantes" e "participação periférica legítima" (Lave \& Wenger 1991). Uma prática social pode ser definida como um mundo gerador de técnicas e de significados compartilhados entre seus praticantes. Nessa perspectiva, uma comunidade de praticantes pode ser entendida como um grupo de determinada prática social. Já a participação periférica legítima seria o modo de ingresso nessa comunidade, envolvendo, simultaneamente, a aceitação dos indivíduos iniciantes pelo grupo e o seu movimento da periferia para o centro da prática, conforme eles adquirem experiência. No caso deste estudo, a "prática social” em questão é a marcenaria; a "comunidade de praticantes" é o grupo que compõe a oficina de Raimundo; e a "participação periférica legítima" analisada foi a de Timóteo.

Já o termo "técnica", empregado neste artigo, representa "um ato tradicional eficaz", sendo que sua definição depende desta característica (Mauss 2003:407). O papel de sua qualidade de tradição é assegurar sua difusão, enquanto a eficácia é o que garante sua aplicabilidade. Uma das características fundamentais do aprendizado é possibilitar que as técnicas possam sobreviver ao afastamento de seus detentores.

São muitas as técnicas que observamos no cotidiano da oficina de Raimundo. Alguns exemplos são a feitura de uma fresa, para dar acabamento às peças de madeira, que envolve o preparo e o uso de uma trave, capaz de sustentar a extremidade da peça, já plainada, e o olhar direcionado às quinas das peças, a fim de verificar sua retidão.

Isso nos remete ao fato de que, no contexto etnografado, o aprendizado pode ser localizado entre os patamares de aprendizagem 1 e 2 sugeridos por Bateson (Oliveira 2016), ou seja, envolve tanto a transferência de respostas conhecidas para novos contextos (patamar 1) quanto a criação de novas respostas em novos contextos (patamar 2). Portanto, o que se aprende no contexto descrito diz respeito às técnicas e às suas possibilidades de aplicação. Não era o caso de aprender a utilizar ferramentas simples, nem de aprender a fazer tamboretes. Não se tratava, pois, de aprender a postura ou a força necessária para desempenhar as tarefas de um marceneiro, mas de aprender a diagnosticar situações e a aplicar técnicas adequadas para a solução dos problemas.

\section{DESCRIÇÃO E ANÁLISE DO CONTEXTO DE APRENDIZADO}

A oficina de Raimundo é uma empresa familiar, que trabalha principalmente por encomendas. Nela atuam, além de Timóteo e Raimundo, um irmão e um filho de Raimundo. Este irmão é vigia e trabalha na oficina apenas nos dias de folga. O filho não recebe salário como um funcionário, apenas paga a madeira que utiliza e tem acesso livre ao maquinário. Timóteo é o único funcionário fixo. Ele e o irmão de Raimundo recebem, por produção, $30 \%$ do valor das obras. Trata-se, portanto, de um contexto social profissional, mas, em grande medida, as relações que ali se desenrolam são familiares. 
O barracão da oficina fica em um terreno adjacente à casa de Raimundo. Não há muro nem cerca que os separe, de modo que o quintal se confunde com o depósito de madeiras e o trânsito entre os microambientes é desimpedido: se, algumas vezes, os netos de Raimundo brincam próximo ao maquinário, outras vezes Timóteo, seu funcionário, entra na cozinha de sua casa para tomar água ou remover a serragem dos olhos. Pela manhã, a sombra da cobertura de telhas do barracão se funde com a de duas grandes mangueiras, que crescem no quintal. No terreno, cães e galinhas ajudam a reforçar o clima rural, ainda que em plena cidade. Isso é algo que diz respeito às origens de Raimundo, o qual não esconde o desejo de morar em seu sítio e de se dedicar à criação de alguns animais. Assim, é evidente a relação próxima que há entre a oficina de marcenaria e a casa de Raimundo, sendo que muitas vezes a primeira parece uma extensão da segunda (Figura 1).

Destoando das demais faixadas da rua, o barracão tem sua única parede, a de entrada, toda feita em madeira. Mesmo havendo uma porta frontal, é comum que clientes da oficina entrem por um portão grande, que dá para o quintal da casa. No interior, a luz pela manhã e à tarde é

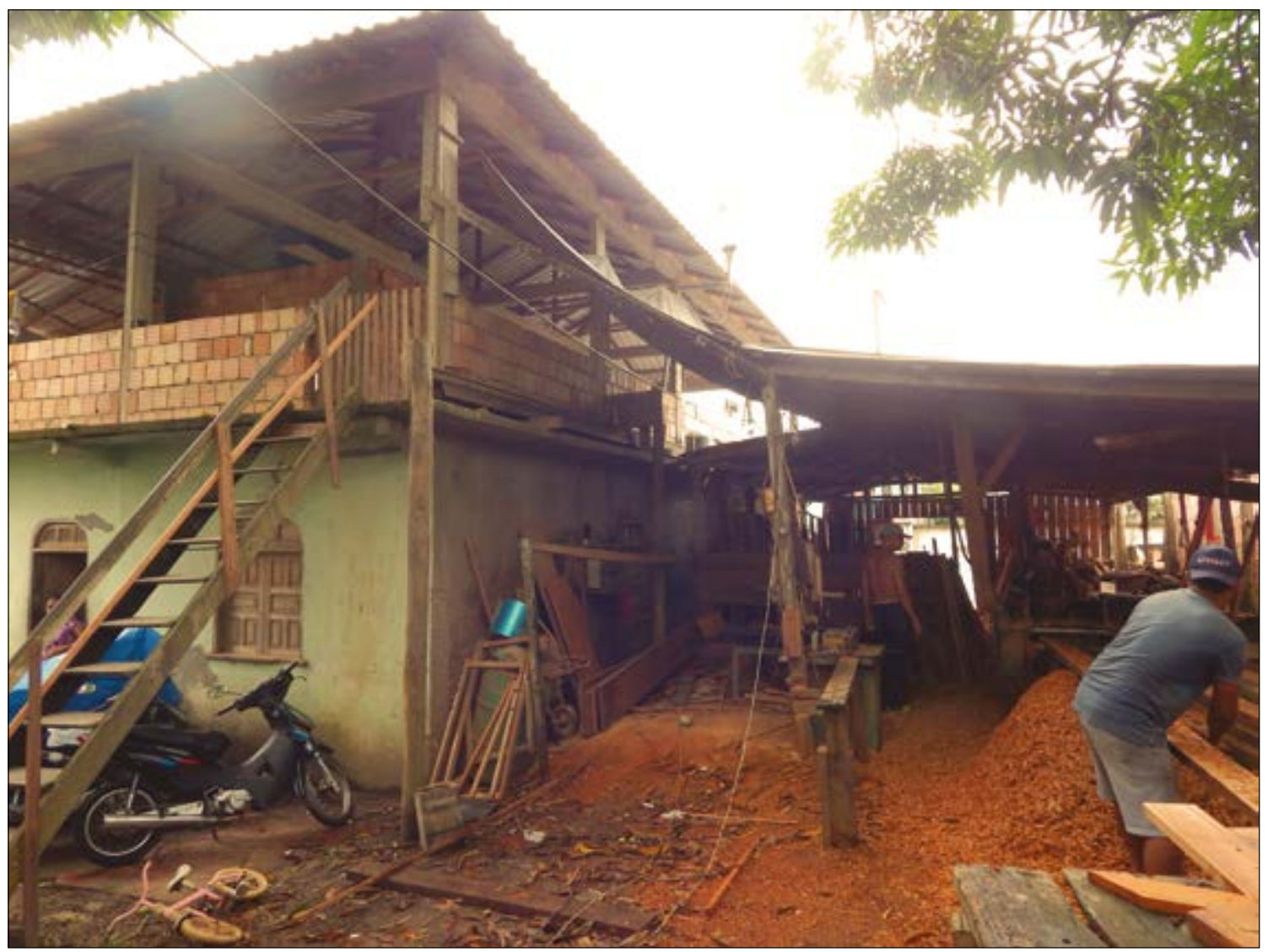

Figura 1 - Visão da oficina a partir do quintal da casa de Raimundo. Foto: Luiz Loureiro (2018). 
sempre amarela e reduzida. Nada, no entanto, que comprometa a visibilidade dos marceneiros (Figura 2). Ali, o maquinário é organizado quase irregularmente, respeitando apenas um caminho central, entremeado por retalhos de madeira, pilhas de serragem e móveis em construção. Sob um telhado de telhas de amianto, um emaranhado de fios conecta cada máquina à rede elétrica. São doze itens, entre bancadas e máquinas, distribuídos com não mais de 2 metros de intervalo entre cada um, em uma área de aproximadamente 7 x $15 \mathrm{~m}$. Como em uma casa de família, ainda que realizando tarefas distintas, nesse espaço um sempre pode observar o que faz o outro.
Raimundo tem 65 anos. É oriundo do baixo rio Juruá e seus avós eram todos seringueiros de origem nordestina. Ele mesmo conta que cortou seringa desde os oito ou nove anos de idade. Antes de se casar, serrou madeira em tora e trabalhou em roças de mandioca. Há 30 anos tem a sua oficina. Conta também que começou no ofício sozinho, sem mestre, e diz que, no início, as coisas eram tão difíceis para ele que até pensou em largar o negócio. Hoje, no entanto, é provavelmente um dos principais marceneiros de Tefé, posição conquistada por meio da aquisição de maquinário único na cidade, como ele mesmo ressalta, e de muitos anos de experiência.

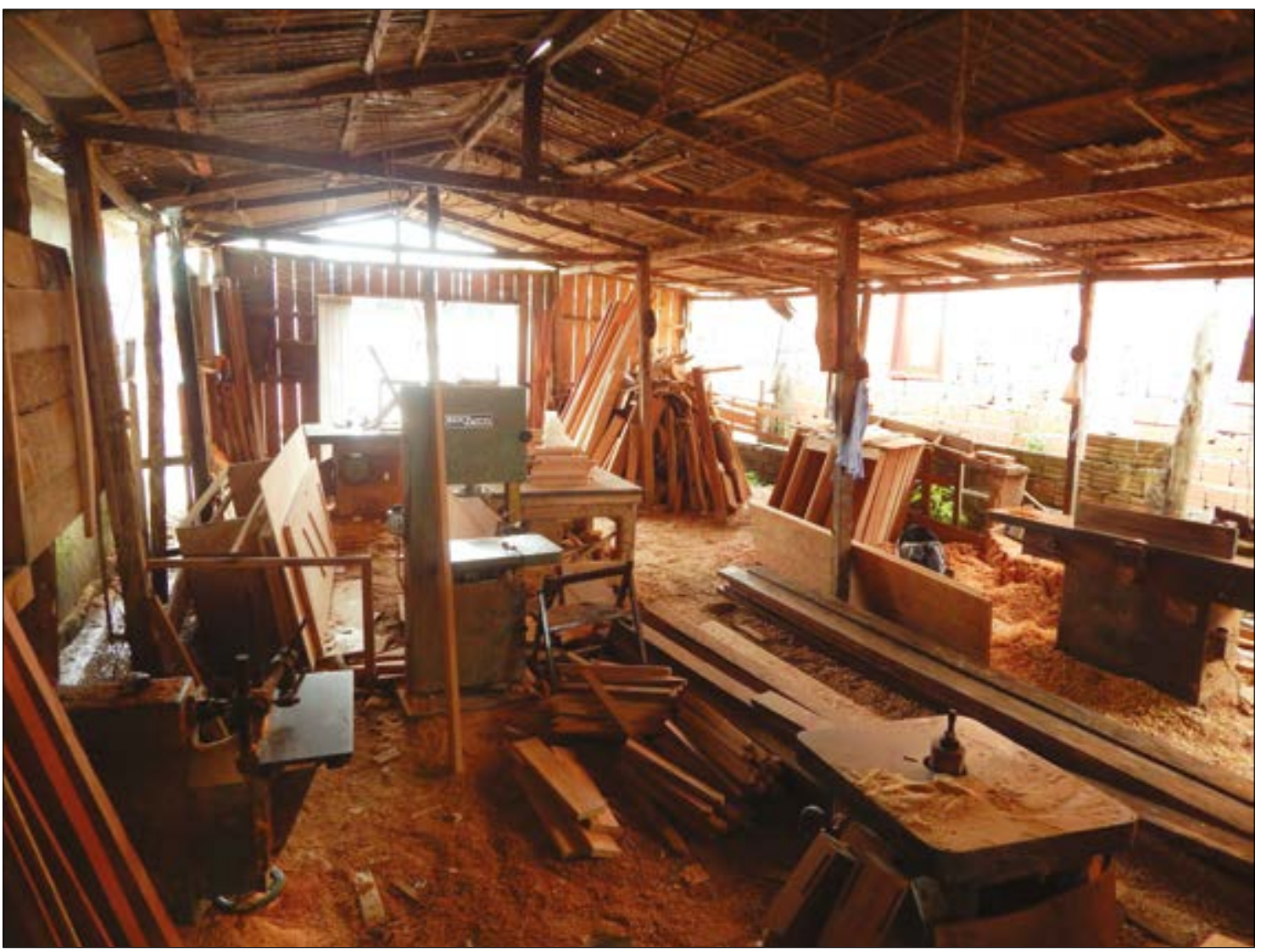

Figura 2 - Interior da oficina de Raimundo. Foto: Luiz Loureiro (2018). 
Timóteo tem 27 anos. Nascido em São Paulo de Olivença, Amazonas, desde os sete anos de idade foi criado em Jutaí. Trabalha desde os 18 anos com madeira, mas tem pouco mais de um ano de serviço na oficina de Raimundo. "Eu não sei muito, quem sabe bem é o sr. Raimundo", disse Timóteo sobre o ofício de marceneiro. Já trabalhou no garimpo e como selecionador de peixes em um flutuante frigorífico. "Eu não achava interessante esse negócio de trabalhar com madeira, comecei porque me chamaram e eu fui. Agora não sei mais o que fazer se não for mexer com madeira”, declarou.

É interessante notar que, apesar de se considerar pouco experiente na marcenaria, colocando-se em posição inferior a de Raimundo nesse assunto, Timóteo parece entender que este é, de forma muito clara, o seu ofício. Tal perspectiva pode ser um importante indício de como tornar-se marceneiro envolve um processo de formação progressiva, que permite tanto o reconhecimento daqueles mais experientes quanto a compreensão de que há um percurso a ser trilhado por meio do que chamamos de engajamento progressivo, no caso de Timóteo indo do desinteresse à completa identificação com o ofício.

Durante os dias de observação, acompanhamos o beneficiamento de algumas vigas, pesadas peças de madeira utilizadas como bases na estrutura de telhados, com medidas de até seis metros de comprimento. Um serviço que Raimundo e Timóteo fizeram juntos.
Nesse caso específico, Timóteo realizou as etapas que demandavam mais força, enquanto Raimundo o orientava. É possível, no entanto, que seja uma prática comum, dadas as idades de cada um. Na divisão das tarefas relacionadas ao início do beneficiamento das vigas, Timóteo ficou responsável por limpar a máquina dos resíduos de um uso anterior, enquanto Raimundo tratou de preparar uma trave improvisada, capaz de sustentar as extremidades que já tivessem passado pela lâmina da plaina desempenadeira (Figura 3).

Depois de um intervalo no serviço para tratar de assuntos pessoais, Raimundo retornou ao improviso, enquanto Timóteo enchia um saco com serragem, que seria dada a uma criadora de galinhas. De volta ao trabalho, Timóteo se aproximou de Raimundo, que lhe deu algumas explicações e passou a instruí-lo no preparo do improviso que fazia: uma trave entre dois pilares de madeira, próprios da estrutura do barracão da oficina, na mesma altura da bancada da plaina.

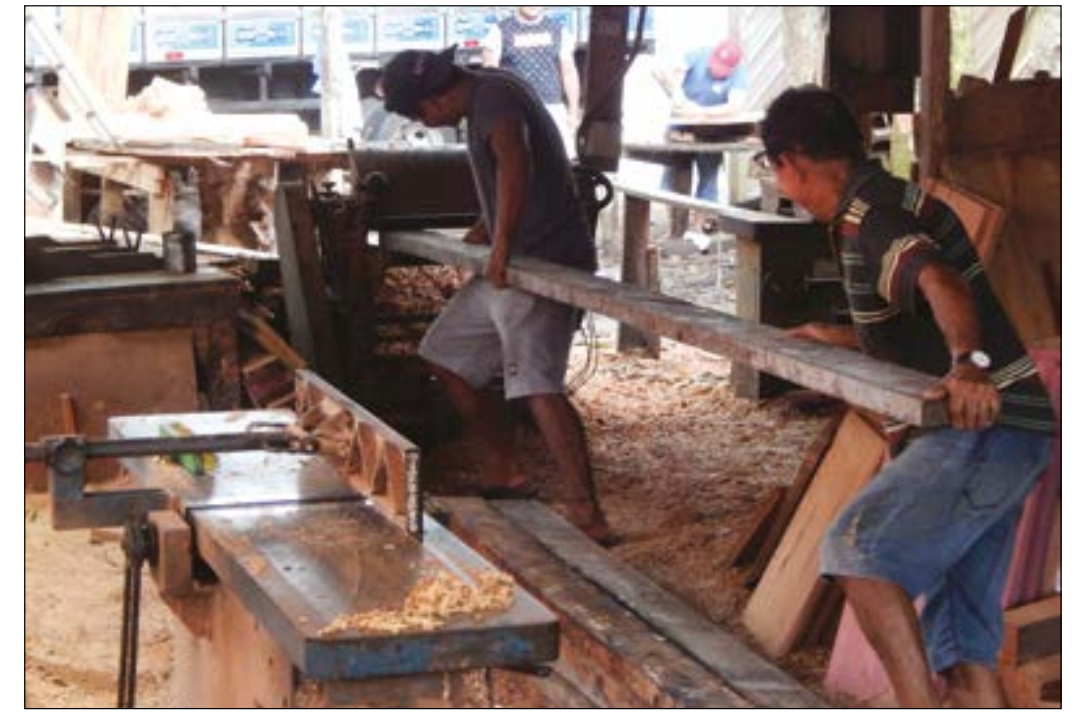

Figura 3 - Raimundo e Timóteo trabalham vigas na plaina desengrossadeira. Foto: Luiz Loureiro (2018). 
Embora viesse agindo como um assistente de Raimundo, houve alguns raros momentos em que Timóteo também determinou ações e papéis. Um exemplo foi uma inversão de papéis entre quem sustentaria a ponta da viga antes que ela chegasse à trave improvisada e quem a empurraria sobre a plaina. A um gesto de Timóteo, Raimundo atendeu prontamente e os dois trocaram de lugar. Não ficou claro a que necessidade correspondia aquela inversão, mas, em todo caso, episódios como este sugerem que não há papéis fixos no desempenho das funções dentro desta comunidade de prática.

Poucas vezes, no período observado, os papéis de patrão e de empregado ficaram evidentes. Apenas nas horas de saída, Timóteo avisava respeitosamente a Raimundo que já havia dado seu horário. Por outro lado, algo que pudemos identificar como determinante nas relações foi o nível de experiência, especialmente entre os dois protagonistas de nossa observação. Mesmo assim, Raimundo e Timóteo conversavam sobre as tarefas que realizavam com muita naturalidade. Uma forma amigável de trabalhar, que pode dizer muito sobre a forma de ensinar e de aprender que se desenrola naquela comunidade de praticantes.

Observamos com frequência que Timóteo opinava sobre as tarefas e Raimundo, se discordasse, explicava porque não era como ele havia dito. De qualquer forma, as opiniões de Timóteo sempre passavam pela validação de Raimundo, demonstrando que ele ainda não tem autonomia para tomar algumas decisões referentes à prática. Aqui não devemos descartar as relações profissionais que se desenrolam neste contexto. Raimundo é, ao mesmo tempo, empregador e dono do maquinário e da matéria-prima com que
Timóteo trabalha. Mas, para além disso, como ficou evidente em certas declarações suas, o respeito pela experiência e a admiração pelas capacidades de Raimundo é que parecem dar a tônica da relação entre os dois. Assim, algumas características das relações entre os dois personagens principais desta etnografia - e a extrapolação das relações entre patrões e empregados, a natureza familiar com que assumem essas relações e uma forma de predominância dos patrões que se tornam uma espécie de "pais" dos grupos de prática se assemelham a características observadas por Ricardo Bresler (1996), na oficina de marcenaria por ele observada.

A análise desse contexto de aprendizagem deve levar em consideração também a experiência prévia de Timóteo, que já não é um iniciante, e sim um praticante com mais de oito anos de marcenaria. Mesmo assim, não devemos descartar que haja aprendizado. Tanto as relações pedagógicas quanto as técnicas de ensino e aprendizagem estavam baseadas no fato de que Timóteo já era um iniciado na prática da marcenaria. Observamos, por exemplo, que Raimundo, na maioria das vezes, não tomava as decisões sozinho e, sempre que possível, analisava e fazia comentários sobre detalhes da prática, junto de Timóteo.

As estratégias para ensinar e aprender foram construídas a partir da experiência de cada um dos envolvidos na prática social em questão. Embora houvesse diferença na perícia resultante de mais ou menos vinte anos de exercício da marcenaria entre os dois praticantes, nem Raimundo agia como um professor, sempre voltado para o ensino, nem Timóteo como um aluno, sempre voltado para o aprendizado. Era, pois, a experiência 
que definia o que um ensinaria e o que o outro aprenderia, sendo que não havia uma relação de instrução estabelecida para todas as ocasiões. O que Raimundo ensinava, ou mostrava, era a forma como um marceneiro com trinta anos de experiência enxergava as situações que se lhes apresentavam, como na noção de educação da atenção de Ingold (2010). Tal constatação nos levou à conclusão de que, em uma prática social como a marcenaria, os diferentes níveis de experiência em cada tarefa são um fator da maior importância para a definição das relações de ensino e aprendizagem, ou seja, é o fator que determina a existência e a forma destas relações.

A experiência de Raimundo transparecia, pelo grande domínio que ele tem sobre os detalhes da prática social: ajustes das máquinas, características das peças trabalhadas e improvisos que facilitam a execução do trabalho. É interessante notar que o improviso, ou a capacidade de improvisar, é um importante aspecto da ideia de aprendizagem apresentada por Bateson (1986), um processo no qual constantemente são elaboradas e aplicadas novas respostas a novos contextos-problema. Os improvisos, que podem ser entendidos como formas de criatividade, seriam, em síntese, demonstrações de domínio sobre o espaço e as técnicas da marcenaria. O que ficou claro é que Raimundo, com sua maior experiência - o que na prática significa maior tempo de aprendizado -, possui grande domínio sobre as técnicas da marcenaria e sobre o ambiente de trabalho.

Já Timóteo, quando perguntado se havia aprendido algo novo na oficina de Raimundo, respondeu que aprendeu principalmente técnicas novas para fazer portas, dar acabamento e formas de tornar o serviço mais eficaz. Questionado se ele saberia dizer quais seriam essas formas, respondeu sorrindo: "já são tantas que agora eu nem vou saber contar uma por uma, mas com certeza são muitas". Além disso, aprendeu a "usar as máquinas, que são diferentes. Em Jutaí tinha máquina também, mas era outro jeito, mais difícil”. Podemos nos perguntar quanto desta maior dificuldade não estaria associado com a menor experiência que possuía na época.

De volta ao beneficiamento das vigas de madeira, foi possível observar que Raimundo não sabe trabalhar apenas com madeira: é ele quem produz, a partir de molas de caminhão usadas, as fresas que dão formas em relevo a pernas de mesa, almofadas de portas e outras obras. É ele mesmo quem concebe e executa a ideia de novas fresas, únicas em suas medidas, linhas e curvas. Aqui temos uma habilidade que é estabelecida a partir da criatividade.

O processo de feitura das fresas é relativamente simples. Ele consiste em marcar, com um lápis sobre a pequena placa retangular de aço - nesse caso, com cerca de vinte centímetros -, o formato desejado e pressioná-la sobre o esmeril que a limará, de acordo com a pressão feita, até as linhas esboçadas. Algo simples, mas demorado e cansativo. Questionado sobre se havia algum molde para aquela fresa, Raimundo, sorrindo, respondeu: "não, não, isso aqui veio foi da cabeça mesmo". A compreensão da tecnologia da prática está, assim, além da mera habilidade de usar ferramentas, sendo mesmo um modo de se conectar com a história daquela prática e de participar de sua vida cultural (Figura 4). 


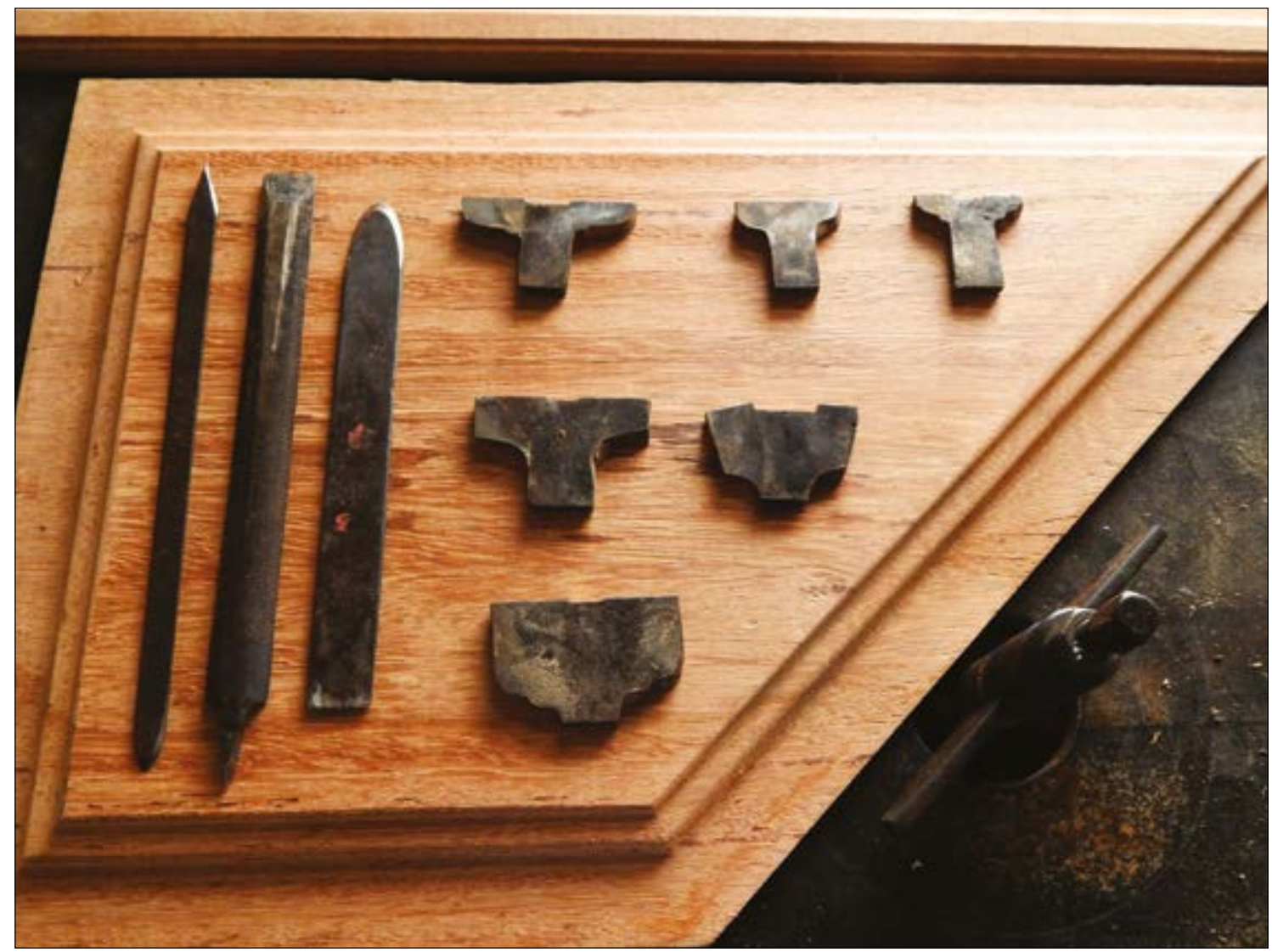

Figura 4 - Fresas feitas por Raimundo sobre peça de madeira que demonstra o resultado da fresa montada na máquina. Foto: Luiz Loureiro (2018).

A prática é, para Raimundo, aliás, uma grande mestra: ele contou que aprendeu a fazer fresas sozinho, "tentando", quer dizer, por meio do método de tentativa e erro. Lembrando sobre como se iniciou no ofício de marceneiro, explicou que:

Tinha um primo da minha mulher que já era marceneiro, mas eu nunca trabalhei com ele. Eu ia até ele, perguntava como é que se fazia e vinha fazer em casa. Por isso eu falo que eu aprendi foi na prática mesmo. Eu comecei fazendo tamborete, e até os primeiros tamboretes eu fiz errado. É bem diferente de quem aprende trabalhando com alguém que já tem mais experiência (Raimundo, comunicação pessoal, 14 jul. 2017).

Esse fato não apenas ilustra o empenho de Raimundo, mas também evidencia a importância da prática para o aprendizado da marcenaria. $\mathrm{O}$ que suas palavras revelam é que, mesmo sem um mestre e uma comunidade de praticantes para se inserir como praticante periférico legítimo, apesar das dificuldades consequentes, é possível tornar-se um marceneiro por meio de uma prática, mais ou menos como a descrita por Jean Lave \& Etienne Wenger (1991), baseada no engajamento, 
quer dizer, na prática interessada. Para o sucesso do processo de tornar-se marceneiro, há uma importante condição, como o próprio Raimundo esclarece:

\begin{abstract}
Não é todo mundo que aprende bem trabalhar com madeira. Tem que ter interesse. Tem um rapaz que me ajuda aqui às vezes, lixando, fazendo serviço simples. Mas ele não aprende nada de novo. É porque ele vem, faz o serviço, mas não tem interesse. Então não é todo mundo que aprende (Raimundo, comunicação pessoal, 12 jul. 2017).
\end{abstract}

Essa declaração demonstra o fato de que replicar as técnicas não torna alguém um marceneiro. Isso porque parte do processo de tornar-se marceneiro envolve a participação ativa, quer dizer, o envolvimento interessado nas atividades que fazem parte da marcenaria. É esse tipo de participação que fornece arsenais para a capacidade criativa dos praticantes deste ofício que, como pudemos observar, é caracterizado pela criatividade e pelo improviso.

Como sugerido por Lave \& Wenger (1991), é o interesse que define o sucesso do processo de aprendizado. Além disso, em comunidades de prática, é o engajamento que permite aos praticantes se legitimarem e, adquirindo experiência, se moverem da periferia para o centro das práticas sociais. Este é um ponto muito importante, pois é a motivação para a aprendizagem que permite a apropriação das culturas próprias das práticas sociais, por meio da elaboração de currículos ou de percursos de aprendizados potenciais, além da experiência, que possibilita o progresso de alguém na prática da marcenaria, por exemplo.

Depois de terminar a fresa usada para dar acabamento nas vigas de madeira, Raimundo conversou com Timóteo sobre o resultado obtido. Eles discutiram sobre a sua forma, os ângulos de suas curvas e o seu provável efeito sobre a madeira. Antes disso, o próprio Timóteo havia destacado o fato de que, diferentemente de muitos marceneiros que dependem de peças prontas, que vêm de São Paulo, era sempre Raimundo quem fazia as fresas usadas em sua oficina. Hoje, Timóteo também sabe fazer fresas.

Sobre aquela recém-terminada peça, os dois decidiram que ela deveria ser experimentada. Foi Timóteo quem montou a fresa nova na máquina, que a girava "como um ventilador". O resultado obtido em um retalho de madeira foi novamente discutido entre eles e, por fim, Raimundo chegou à conclusão de que alterações seriam necessárias, e voltou ao esmeril.

Em uma conversa sobre marcenaria, Timóteo contou que algo que acha muito interessante nessa profissão, e que em sua opinião a difere das demais, é a criatividade. Revelou que gosta de imaginar que a madeira que ele está trabalhando provavelmente veio de muito longe, e agora está ali, para que ele crie alguma coisa com ela. E, em seguida, o filho de Raimundo acrescentou que a marcenaria não é um trabalho que estressa. Ela, na verdade, dá prazer a quem a pratica. A isso, Raimundo acrescentou, retomando a ideia da criatividade, que não se trata apenas do prazer de criar, pois "a criatividade chama o freguês".

Sobre essa noção mais prática a respeito da criatividade, Raimundo ofereceu dois exemplos 
ilustrativos. O primeiro deles foi o fato de que, há algum tempo, só se fazia um modelo de porta na marcenaria de Raimundo, mas hoje, por outro lado, eles produzem pelo menos cinco tipos diferentes, $\mathrm{e}$ então outras pessoas, com preferências diferentes, podem gostar e comprar seu trabalho. O segundo exemplo dado por Raimundo foi o das "cadeiras de fechar", que ele está começando a produzir: "antes eu nunca tinha feito, não sabia fazer. Agora já tenho até encomenda", disse, apontando para uma pilha de armações, explicando que no começo só precisou de um modelo para se basear.

Questionado se havia algo que poderia ser considerado um problema na profissão de marceneiro, Timóteo disse que se ela pode ser prazerosa, por outro lado, é uma profissão que pode prejudicar a saúde do praticante, por causa do pó que o marceneiro inala todo dia. Aqui, devemos acrescentar que o uso de equipamentos de proteção individual entre os artesãos não foi observado. À declaração de Timóteo, no entanto, Raimundo retrucou que, na realidade, toda profissão tem disso: "é assim também para quem mexe com ferro, quem mexe com vidro. Todo trabalho tem o seu lado ruim". O que transpareceu deste ponto é que, para ambos, o lado negativo das profissões parece estar principalmente relacionado a riscos e possíveis prejuízos à saúde dos profissionais.

Outro assunto que surgiu nesta conversa foi o desmatamento, que Timóteo disse achar ser outro ponto negativo da marcenaria. A esse respeito, Raimundo também tinha sua opinião. Disse que o verdadeiro problema "é a madeira que vai para fora", porque "aqui na marcenaria, sendo bem planejado, a gente passa até um ano inteiro usando só quatro árvores de madeira”. Em sua opinião, mais danoso seria o que vai para outras regiões ou o que é derrubado para fazer roça e pasto, "porque muita árvore boa, que ninguém vai poder usar, se perde". Segundo ele, isso é um problema sério, pois “a culpa sempre cai nos pequenos”, quer dizer, sobre marcenarias como a sua.

Raimundo disse, ainda, que na marcenaria o lucro sempre é pequeno, mas constituindo freguesia tudo melhora. Ou seja, a rede de contatos estabelecida ao longo dos anos e o prestígio adquirido com a experiência são os fatores que possibilitam a manutenção do empreendimento. É por isso também que o marceneiro tem que ser honesto, afirmou. É preciso ser correto com o dinheiro dos clientes e não pegar serviços que não são possíveis de serem executados. Assim se constrói freguesia, assinalou.

Para ele, o lado negativo da marcenaria é que sempre falta capital e não há incentivos do governo para esta classe de trabalhadores. A esse respeito, Raimundo revelou que gostaria de ter um galpão maior e de vender seu trabalho para fora de Tefé, mas que, sem algum tipo de financiamento no início, se torna muito difícil realizar esses desejos.

Os principais problemas para a marcenaria, na visão de Raimundo, são, portanto, a falta de recursos e a "perseguição". Ele assinalou que a falta de recursos sempre afeta mais as empresas pequenas, familiares, como a sua, porque elas não têm capital de giro para investir em reformas necessárias nos galpões ou em renovação do maquinário, que se torna velho e pouco eficiente. Já a "perseguição" (que pode ser entendida como a fiscalização do setor madeireiro) se expressa na dificuldade em conseguir, na cidade, madeira manejada, situação que sugeriu que poderia ser 
resolvida com a facilitação de planos de manejo na região. "É por causa da burocracia que o negócio não cresce", concluiu.

Aqui, podemos acrescentar que a crítica de Raimundo se aproxima, de certa forma, da realizada por João de Araújo (2011). Analisando a invisibilidade dos trabalhadores do setor marceneiro de Xapuri, no Acre, este autor sugere que, a fim de contornar certas contradições do desenvolvimento na Amazônia brasileira, as perspectivas do manejo florestal não podem perder de vista parcelas da população urbana que representam riscos diminutos à conservação e dependem do recurso madeireiro para a manutenção de sua prática social.

De volta às perspectivas dos praticantes, para o filho de Raimundo, por exemplo, que já é pai de família, ainda que a marcenaria seja uma boa profissão, ela não deve ser seu único "ganha pão". Seu desejo parece resultado de algo que ficou claro também em declarações de seu pai, para quem, apesar do excepcional maquinário para o perfil da marcenaria tefeense, a prática do ofício já não é tão recompensadora em seu sentido econômico, como foi outrora. Assim, parece plausível a hipótese de que empresas familiares, como a de Raimundo, ainda que sejam um modelo frequente em Tefé, têm tido dificuldades em se adequadar ao processo de modernização da cidade.

$\mathrm{O}$ que foi dito nessa conversa ilustrou tanto como estes praticantes se entendem dentro de sua prática quanto como eles compreendem sua prática no mundo, dando indícios da identidade profissional reproduzida naquela comunidade. Se, por um lado, a marcenaria é por eles relacionada com a criatividade e o prazer, por outro está reconhecidamente desvalorizada. Um caminho, segundo Raimundo, pode ser deixar de lado os trabalhos com madeira e ingressar nos negócios com MDF (sigla internacional para placa de fibra de média densidade), um material mais barato e que tem a procura em ascendência. Com isso, alguns elementos próprios da prática da marcenaria serão alterados, mas também devemos nos lembrar que adaptações a novos contextos são condições para a reprodução de práticas sociais. Mas essa é apenas uma possibilidade. Os verdadeiros resultados, apenas o tempo poderá revelar.

\section{CONSIDERAÇÕES FINAIS}

Consideramos que a reprodução social desta prática está, como buscamos demonstrar ao longo deste artigo, baseada no aprendizado. Isso porque o que se aprende em grupos de praticantes, como a oficina de Raimundo, inclui técnicas próprias da marcenaria e a identificação com o ofício de marceneiro. $\mathrm{O}$ aprendizado é fundamental, portanto, porque permite que os indivíduos tenham acesso a grupos nos quais circulam técnicas e são elaborados significados sociais para o ofício, quer dizer, proporcionam tanto o autorreconhecimento destes indivíduos como praticantes da marcenaria quanto compreensões sobre como esta prática é entendida pela sociedade.

Além disso, ficou clara a importância da experiência na estrutura da prática social e no sistema de relações que compõe a comunidade de praticantes que observamos. Como ficou patente, o papel central da experiência pode ser atribuído tanto ao fato de ser esta qualidade a responsável por determinar a posição dos sujeitos nesse 
sistema de relações quanto à sua característica de definir as estratégias pedagógicas que deverão ser adotadas ao longo do processo de aprendizagem. Além disso, é a experiência resultante de longo período de engajamento na prática que confere aos indivíduos maior conhecimento sobre situaçõesproblema e possíveis soluções, o que contribui para a capacidade de improvisar e de criar com a madeira. E é essa capacidade que confirma o sucesso dos indivíduos no ofício, permitindo que se movam da periferia para o centro desta prática social.

Outros fatores também merecem destaque. Um deles é a forte relação entre a casa e a família de Raimundo e a oficina, algo que revela uma característica importante da prática da marcenaria na região, onde o trabalho destes artesãos se desenrola em oficinas localizadas nos quintais de casa ou em terrenos adjacentes, com a participação de parentes próximos e de funcionários que acabam se tornando, de certa forma, agregados do grupo familiar. Outro fator importante é a identificação e o engajamento de Timóteo nesta que pode ser, a despeito de reconhecidamente uma profissão menos rentável do ponto de vista econômico, a profissão de sua vida. Tanto o tom familiar que possuem ou assumem as relações desenvolvidas em oficinas como esta quanto a identificação com um ofício caracterizado como criativo são indicativos de por que a marcenaria, nos moldes observados, pode ser considerada um oficio que dá prazer a quem o pratica. Casos como este são uma importante prova da vitalidade de práticas sociais que, apesar dos constrangimentos impostos pela modernização, seguem adaptando suas técnicas e reinventando seus significados.

\section{AGRADECIMENTOS}

Agradecemos a Timóteo e a Raimundo e sua família, por nos receberem e colaborarem conosco. Ao Programa de Pós-Graduação Interdisciplinar em Ciências Humanas da Universidade do Estado do Amazonas (UEA) e ao Instituto de Desenvolvimento Sustentável Mamirauá (IDSM), pela infraestrutura cedida, e à Coordenação de Aperfeiçoamento de Pessoal de Nível Superior (CAPES), pela bolsa de pesquisa concedida ao mestrando.

\section{REFERÊNCIAS}

Araújo, J. M. 2011. Novas contradições do desenvolvimento na Amazônia brasileira: a indústria florestal e a invisibilidade dos trabalhadores do setor marceneiro de Xapuri. Anais do Circuito de Debates Acadêmicos CODE/ IPEA (1):1-16.

Bateson, G. 1986. Mente e natureza: a unidade necessária. Rio de Janeiro: Francisco Alves.

Bresler, R. 1996. Identidade e vínculos em uma oficina de marcenaria. São Paulo: Núcleo de Pesquisas e Publicações/FGV-EAESP.

Geertz, C. 1989. Uma descrição densa: por uma teoria interpretativa da cultura, in $A$ interpretação das culturas, pp.3-24. Rio de Janeiro: LTC.

Gomes, A. M. R. 2014. Um (possível) campo de pesquisa: aprender a cultura, in Diálogos sem 
fronteiras: história, etnografia e educação em culturas ibero-americanas. Organizado por S. P. Tosta e G. Rocha, pp. 205-220. Belo Horizonte: Autêntica Editora.

Ingold, T. 2010. Da transmissão de representações à educação da atenção. Educação 33(1):6-25.

Lave, J., e E. Wenger. 1991. Situated learning: legitimate peripheral participation. New York: Cambridge University Press.

Marcos, V., e N. Peralta. 2016. Empreendimentos tranformadores de madeira da microrregião de Tefé: características e desafios. Anais do Simpósio sobre Conservação e Manejo Participativo na Amazônia (13):1-19.

Mauss, M. 2003. As técnicas do corpo, in Sociologia e antropologia, pp. 399-424. São Paulo: Cosac Naify.

Oliveira, M. C. 2016. Aprendizagem e comunicação em Bateson: a exigência de uma epistemologia formal e complexa. Trans/Form/Ação 39(1):93118. DOI: http://dx.doi.org/10.1590/s010131732016000100006 .

Ribeiro, E. M. 1950. Profissiografia de marcenaria. Arquivos Brasileiros de Psicotécnica 2(2):73-82. 